\title{
Focus on Methodology: Let's talk about discourse analysis for health professional education: What, why and how
}

\author{
Robyn Woodward-Kron
}

\begin{abstract}
Much of healthcare is facilitated through interactive talk and writing: diagnosing, collaboratively making treatment decisions, conducting treatment, coordinating care, handing over care. For junior health professionals, learning the valued patterns of talk and writing - the discursive practices of healthcare-is part of becoming a health professional. Discourse analysis of texts, written and spoken, can make visible to health professional educators what the valued interactional patterns are and how junior members learn the discursive practices through interaction with more senior colleagues. It can also illuminate "troubles" in communication, such as barriers, power imbalances and misalignment. Doing discourse analysis requires an understanding of how texts work and a meaningful, systematic approach to representing and analysing data. This paper introduces genre theory, a form of discourse analysis that distinguishes between text types according to their social purpose and contextual variables, including what the text is about, who is involved and how the text is organised. This paper outlines some principles of genre analysis and practical "how to" guidelines. It also provides suggestions about how findings of genre analysis can inform teaching in health professional education.
\end{abstract}

Keywords: discourse analysis; health professional education; genre analysis; communication 


\section{Introduction}

Health professional students and trainees engage with and produce a multitude of spoken and written texts as part of their university and clinical learning. Students and teachers have a shared understanding of the purpose and structure of these texts, how to engage with them and how these texts are integral to more complex and extended communicative events. For example, problem-based learning (PBL) case notes anchor the tutorial discussion of the patient's problem and patient interviews inform case presentations. This shared but often tacit understanding is a result of students' socialisation into the pedagogical discourse that instructs and regulates learning (Bernstein, 1990). When students transition to clinical practice, the texts and communicative events in which they engage will have the primary goal of doing healthcare rather than learning to do healthcare. Becoming an integral participant in the healthcare community of practice also involves joining a new discourse community, with its concomitant texts and discursive practices.

Discourse analysis of texts, both written and spoken, and of extended communicative events, such as a multidisciplinary team meeting, can make visible to health professional educators the role of language and communication in students' learning and clinical practice. It can also provide an explanatory lens on, for example, how junior members learn the talk through interaction with more senior colleagues. More critically, discourse analysis of clinical interactions can identify barriers to effective communication and to students' legitimate peripheral participation (Lave \& Wenger, 1991), such as inter and intraprofessional power dynamics, and student misunderstandings about communicative goals and values. In addition to these research functions of describing, explaining and critically analysing, discourse analysis can complement other qualitative approaches to research in health professional education (HPE), such as interview studies, by providing discursive evidence that may confirm, illuminate, contradict or show gaps between perceptions of practices and lived experiences. The purpose of this paper is to introduce discourse analysis and some of its applications in HPE research. Genre analysis - a form of discourse analysis that distinguishes between text types according to their social purpose and register variables, including what the text is about, who is involved and how the text is organised-is introduced in more detail as one approach that may resonate with HPE researchers. Genre analysis, it will be argued, provides an accessible "way in" for researchers interested in the role of language and communication for learning, in order to inform pedagogy and practice in HPE.

\section{What is discourse analysis?}

Discourse study, viewed broadly, is the study of authentic or naturally-occurring language in use. It is sensitive to the context of use, such as the pedagogic context of a classroom or the scientific context of a discipline, and it is concerned with patterns of language use to construe meanings-knowledge, relations, values, activities. Discourse analysis seeks to identify patterns of meaning making through language, with reference to context. The study of discourse is not a homogeneous field, and it is made richer by contributions informed by critical theory, philosophy, rhetoric and linguistics. These disciplinary 
differences are reflected in researchers' analytical tools and theoretical framing, with the choice of approach informed by the research questions and disciplinary expertise of the researcher. My own disciplinary orientation is linguistics and education, called educational linguistics (Christie, 1994; Martin, 1993; Rose, 2014), so my approach to texts foregrounds language as a semiotic system and focuses on functional linguistic analysis to investigate learning as a social activity. Other socially-oriented approaches can have a more rhetorical or metaphorical focus with less linguistic emphasis and, therefore, a detailed knowledge of language systems (e.g., phonology, lexicogrammar, discourse semantics) is not required to undertake analysis. Discourse analysis lends itself to close examination of both micro-discursive patterns and more macro perspectives. It can accommodate large datasets, or corpora, which are analysed with the assistance of software, enabling counting of discursive features across the datasetfor example, certain types of speech functions (e.g., questions, statements), evaluative language or markers of politeness. Discourse analysis approaches tend to be informed by existing research that provides the analytical framework.

The following section gives some examples of discourse analysis in HPE research, focusing on the approach to analysis and how the data is presented. The purpose is primarily to raise awareness about the application rather than to evaluate or critique. The focus is first on two-way, or dyadic, encounters, then on communicative events with multiple participants.

\section{Discourse studies in HPE research}

Despite their artificiality, roleplays for teaching and assessing student-patient communication are an authentic institutional genre in HPE and are, thus, of interest to the HPE discourse analyst. How do simulated patients (SPs) guide students in roleplay interactions to allow students to show their competence? This was one of the questions addressed in De la Croix and Skelton's (2013) study of medical student-SP roleplays. Their analysis was informed by established linguistic markers of conversational dominance, such as topic initiation and questioning. The roleplays were transcribed noting line or speaker turns and using conventions to capture the dynamics of the interactions, such as speaker overlaps or interruptions (//), length of pauses (x seconds) and non-verbal behaviour (e.g., laughs). Such a detailed transcription is time intensive but helps to bridge the gap between, for example, interpersonal meanings evident in an audio or video recording compared to those that can be gleaned from a transcript. It also informs the presentation of the results; for example, in the De la Croix and Skelton study, 
excerpts showing overlaps, nodding and use of pauses were included as SP discursive strategies to indicate "permission" for the student to close the interaction. The textual analysis of the large dataset of 100 transcripts was carried out with software. Roberts et al. (2003) used a similar granular analysis approach informed by sociolinguistics and conversational analysis in their study of "good" and "poor" communication in medical student OSCEs. The discourse analysis sheds light on patterns of communicative approaches evident in higher scoring versus lower scoring students, such as an empathic approach as opposed to an interpersonally-remote style.

The dyadic encounter can also be analysed discursively from a more macro perspective. Using a rhetorical approach to discourse and grounded theory, Lingard et al. (2003) examined paediatric trainee case presentations to analyse how novices are socialised into the discursive practices of medicine. Audio-recorded case presentations and participant interviews formed the data. The rhetorical approach informed by a framework of content, context (occasion), purpose and audience is described in detail in Lingard (2007). Rhetorical genre analysis utilised with "communities of practice theory" was the approach in J. Brown et al.'s (2018) study to examine general practice trainee helpseeking supervisory encounters. Broadly, genre analysis as a form of discourse analysis is attentive to the whole interaction and the discourse patterns that contribute to the whole as part of a social process. In these studies, the genres of the case presentation and the supervisory encounters, respectively, were the text "types" under investigation. The macro lens provided by the rhetorical genre approach in J. Brown et al.'s study made visible the recurring dominant interactional patterns between trainee and supervisor.

The discussion of discourse research has so far focused on two-way interactions. The micro and macro perspectives have also been the focus of learning encounters with multiple participants. The teaching and learning triad of student-tutor/clinical educator-patient was the focus of a discourse study by Rees and Monrouxe (2008). Their analysis concentrated on pronominal use (e.g., I, we, you) to investigate interpersonal and power relationships between participants. The analytical approach was underpinned by complementary socio-linguistic theories, including critical discourse analysis (Fairclough, 2001), politeness theory (P. Brown \& Levinson, 1987) and Goffman's (1981) drama informed work on roles and identities. In contrast, Tai et al.'s (2019) study of audiology interactions adopted a linguistically-oriented genre approach to provide a macro perspective of how students and their clinical teachers co-construct the clinical interview. Informed by genre theory (Eggins \& Slade, 1997; Martin, 2001), Tai et al.'s study involved transcribing the video-recorded studentpatient-clinical educator interactions, identifying the stages of the interaction and how the participants contributed to the discursive goals of each stage. Pedagogies that are explicit in their approach and values, such as PBL, have also received attention by genre researchers who have examined the dynamics of participation in classrooms where learning is co-constructed (Imafuku \& Bridges, 2016; Imafuku et al., 2014; Woodward-Kron \& Remedios, 2007). In educational research more broadly, classrooms have, not surprisingly, been a major area of discourse study (Christie, 2002; Mehan, 1979; Sinclair \& Coulthard, 1975). 
What is surprising in HPE research is the limited focus on students' written texts in either the university or clinical setting. There is some discourse research on institutional HPE policies and practices, such as competency based assessment (for example, Boyd et al., 2018) and accreditation standards (Whitehead et al., 2014), but there is little research focusing on students learning through writing. Some examples of discourse analysis of HPE policy and practice include development of professional values as reflected in written assessments (Howe et al., 2009) and feedback conversations on healthcare research writing (Woodward-Kron, 2007). Assessment genres yield a range of authentic texts, such as short answer questions, reflections, research reports and case studies. Unlike spoken interactions, written texts come "pre-packaged" for discourse analysis, not requiring time intensive transcription before the analysis can commence. While ethics approval is required to research written texts, there may be fewer hurdles in accessing the texts and permissions; it may also be less intrusive for participants. A discourse perspective on student or trainee writing as a lens on becoming a professional and joining the discourse community (Woodward-Kron, 2004, 2008) is an area equally worth HPE discourse analysts' attention.

\section{Genre theory: An accessible approach to discourse analysis for HPE researchers}

The following section introduces a form of discourse analysis called genre theory, which I use in my own discourse-oriented research of health professional student/trainee interactions with other health professionals and with patients. It is an approach that is equally suited to written or spoken texts. I have introduced this form of genre analysis to graduate research students with HPE backgrounds to assist their research enquiries. This experience has encouraged me to believe that the genre theory approach to discourse analysis is accessible not only for HPE researchers but that the findings of such an approach can also resonate with health professional educators. Before describing genre theory, I note that it is not my intention to argue that one form of discourse research is superior to another, echoing Dornan (2014). My experience has led me to conclude that genre theory is an approach that researchers can delve into, with the depth and extent of their analysis (in terms of linguistic orientation) only constrained by researchers' expertise and/or the extent of their interdisciplinary research partnerships.

Genre theory as developed by functional linguists concerned with language and literacy education views genres as staged, goal-oriented social processes (Christie, 2002; Martin, 1997; Rose, 2014). Viewed simply, genres can be characterised as recurring text types with recognisable language features. For example, health professionals, health professional educators, students and patients are familiar with the patient consultation as a goal-oriented encounter (identify the problem, agree to a management plan), which tends to have identifiable functional stages (opening, gathering information, proposing a diagnosis, treatment/or agreeing to a management plan, closing). Drawing attention to the valued structure of professional interactions is a teaching strategy to induct novices into the expected patterns of interactions, for example, in the Calgary Cambridge guide content and process approach to the medical interview (Kurtz \& Silverman, 1996); therefore, an analytical approach that seeks to make visible the stages 
of spoken or written genres can provide a firm foundation for practitioners researching their disciplinary practices. The second aspect of genre theory is its relation to context. In functional linguistics (Halliday, 1978), the social contexts of language have the dimensions of field (the "what" of the text), tenor (who is involved) and mode (how field and tenor are organised). In genre theory, field, tenor and mode are the contextual register variables. Field is to do with the language choices to represent the content or activity, such as technical or everyday language for the people and things in the text. Tenor describes the role relations between participants, such as status, degree of contact and affect. Mode indicates spoken dialogue or spoken or written monologue. Genre analysis, therefore, characterises a genre in terms of its functional schematic stages and in terms of its recurrent contextual features - the register variables. A further element is the relation between the register variables and Halliday's (1978) metafunctional theory of language, which views language as organised to make three kinds of meanings: experiential, interpersonal and textual. The register variables are realised through these language metafunctions, with field corresponding to experiential meanings, tenor with interpersonal meanings and mode with textual meanings. For the researcher willing and able to engage with the language features of a genre, register (and the corresponding language metafunctions) provide the analytical tools for a systematic exploration.

\section{Getting started with genre analysis}

\footnotetext{
Analytical procedure for genre analysis

1. Identify the overall purpose or goal of the genre.

2. Identify the predictable main stages and substages in the text.

3. Provide a rationale for delineating between stages, e.g., shifts in function, topic, speaker.

4. Identify the order of the stages and which stages appear to be optional or are recursive.

5. Provide functional labels to the stages and substages to describe how they contribute to the genre.

6. Provide a description of the field, tenor and mode variables, noting for example, variation in lexicogrammar for each stage or speech function (e.g., clarifying).
}

Eggins and Slade (1997) provide an accessible account of undertaking genre analysis, which can be adopted for written and spoken genres. After transcribing spoken texts and taking account of any transcription conventions relevant to the research question (e.g., overlapping talk), the next task is to identify the predictable main stages and substages. In written texts, this might be facilitated by subheadings, such as "patient identification" in a discharge summary, or signalled lexically in a spoken interaction, that is, "Let's talk about treatment options". The functional labels may not correspond to the labels normally assigned by the participants, such as past medical history or social history in a consultation. Further, identifying the stages and labelling them functionally is a recursive process, which can benefit from discussion with participants or other informants. To make the process of doing genre analysis more transparent, the next section draws on two case studies - supervised student-patient audiology hearing assessments (Tai et al., 2019) and international medical graduate (IMG) intraprofessional telephone communication (Pryor \& Woodward-Kron, 2014). Both studies were undertaken by graduate research students-Tai, whose background is audiology, and Pryor, who has a background in speech pathology and language education. 


\section{Supervised student-patient audiology hearing assessments}

How do audiology students co-construct a hearing assessment with patients while supervised by a clinical educator? This was one research question guiding Tai et al.'s (2019) study. As there were no known observational studies of the triadic communication with an educator, student and patient, the researchers brainstormed what the functional labels for the schematic stages might be in order to guide the initial analysis. The labels of "information gathering", "providing a diagnosis" and "management planning" were adopted. Close analysis of the interactions and attention being paid to which speaker initiated a topic shift resulted in the identification of functional substages, including those in which the clinical educator intervened to elaborate, repair and summarise for the patient. Table 1 shows the management planning stage, with the optional substages

\section{Table 1}

Genre Stages for Hearing Assessment (modified from Tai et al., 2019)

\begin{tabular}{|c|c|c|}
\hline $\begin{array}{l}\text { Management } \\
\text { Planning }\end{array}$ & Communication Task & Sample Text Excerpts \\
\hline \multicolumn{3}{|l|}{ Recommendation } \\
\hline \multirow[t]{2}{*}{$\begin{array}{l}\text { Provision of } \\
\text { recommendations }\end{array}$} & $\begin{array}{l}\text { Offer recommendation options and processes } \\
\text { involved }\end{array}$ & $\begin{array}{l}\text { "If you are having difficulty in situations ..., } \\
\text { there are options that you can look into [such } \\
\text { as] hearing aids" (S1). }\end{array}$ \\
\hline & $\begin{array}{l}\text { Check patient's receptiveness and } \\
\text { perspectives to recommendation(s) }\end{array}$ & $\begin{array}{l}\text { "So, do you feel like you want to do something } \\
\text { about [your hearing loss]?" (S12). }\end{array}$ \\
\hline $\begin{array}{l}\text { *Providing } \\
\text { alternative } \\
\text { recommendations }\end{array}$ & $\begin{array}{l}\text { Offer another option if the patient is doubtful } \\
\text { towards the initial recommendation }\end{array}$ & $\begin{array}{l}\text { "It's up to you whether you want to have a } \\
\text { chat with someone about hearing aids.... } \\
\text { There are a couple of things that you can do to } \\
\text { help you communicate with people" (S11). }\end{array}$ \\
\hline \multicolumn{3}{|c|}{ Summary \& Repair } \\
\hline \multirow[t]{4}{*}{ CE intervenes } & Checking patient understanding & $\begin{array}{l}\text { "Can I just jump in? [Patient], do you } \\
\text { understand these results? (CE of S8). }\end{array}$ \\
\hline & Explain process (next steps) & $\begin{array}{l}\text { "You can wait until after you see the ear, nose } \\
\text { and throat specialist to book the other test in" } \\
\text { (CE of S20). }\end{array}$ \\
\hline & $\begin{array}{l}\text { Summarise results and correct any patient } \\
\text { misunderstanding }\end{array}$ & $\begin{array}{l}\text { "Given that there is a difference between the } \\
\text { ears, it might be worthwhile doing ... another } \\
\text { test that can give us more information" (CE } \\
\text { of S13). }\end{array}$ \\
\hline & Offers explanation to patient concerns & $\begin{array}{l}\text { "Sometimes you get a bit of crackling with the } \\
\text { Eustachian tube" (CE of S1). }\end{array}$ \\
\hline \multicolumn{3}{|l|}{ Closing } \\
\hline End appointment & $\begin{array}{l}\text { Signal end of the appointment and direct } \\
\text { patient back to the reception area }\end{array}$ & $\begin{array}{l}\text { "Alright, so that's everything we need to do } \\
\text { today. If you don't have any other questions, } \\
\text { I'Il take you back out the front" (CE of S8). }\end{array}$ \\
\hline
\end{tabular}

${ }^{*}$ = optional stages or functions, $(S)=$ student, $(C E)=$ clinical educator 
and recurrent substage of "summary and repair", initiated by the clinical educator. The table includes a column with the communication tasks or activities that contribute to realisation of the stage and sample text excerpts from the data. The findings of the genre analysis showed the importance of clinical educator contributions for co-constructing the hearing assessment appointment and for students' learning through talk with a more experienced clinician. It also showed a need for professional development with clinical educators to help them devise a range of strategies for repair that allow more student involvement in the latter phase of the hearing assessment.

\section{International medical graduate (IMG) communication}

International medical graduates (IMGs) from non-English speaking backgrounds can face language and cultural barriers transitioning to new workplace settings. Pryor and Woodward-Kron's (2014) study examined effective intraprofessional communication in a consultation call between trainees and a senior doctor in a simulated setting. To determine what was deemed effective communication, the researchers reviewed the audio recordings and transcripts with a senior participating doctor to identify the stages in a successful call. Genre analysis was undertaken, including comparing all the calls with the generic structure of the successful call. In addition, this study examined the language features for each stage. Table 2, from the study, shows the generic stages (middle column), with the contributions of each speaker shown for each stage. The register and more detailed linguistic analysis for each stage compared the realisations of the successful or effective calls compared to the calls deemed unsuccessful.

\section{Table 2}

Interaction in the Generic Stages of the Medical Telephone Call Consultations (from Pryor \& Woodward-Kron, 2014, p. 46)

\begin{tabular}{l|l|l}
\hline Interactional Dimension (IMG) & Generic Stages & Interactional Dimension (SD) \\
\hline Greets \& identifies self & Doctor identification & Greets \& identifies self \\
\hline $\begin{array}{l}\text { Gives information about the patient } \\
\begin{array}{l}\text { States core clinical issues and } \\
\text { management strategies }\end{array}\end{array}$ & $\begin{array}{l}\text { Patient identification } \\
\text { presentation }\end{array}$ & Acknowledges information \\
\hline Requests advice or assistance & Purpose & Acknowledges information \\
\hline Suggests possible cause & Diagnostic hypothesis & $\begin{array}{l}\text { Accepts suggestion or offers } \\
\text { alternatives }\end{array}$ \\
\hline Answers questions, offers information & Information gathering and checking & $\begin{array}{l}\text { Requests information; clarifies, } \\
\text { checks and restates }\end{array}$ \\
\hline Acknowledges & Management plan & Gives instructions \\
\hline Acknowledges & Statement of intent & States intended action \\
\hline Expresses thanks/says goodbye & Closing & Says goodbye \\
\hline
\end{tabular}

IMG = international medical graduate, $\mathrm{SD}=$ senior doctor 
In the less successful calls, in the highlighted field of "patient's current clinical presentation", there was increased interactivity, with statements and questions from the senior doctor, who interrupted the trainee (see the latching $==$ in Table 3, indicating follow-on or overlapping speech). This was interpreted as teaching sequences, with one strategy of the senior doctor identified as recasting or reinterpreting information. Linguistic analysis for the variable of field (the content) noted the presence of the conjunctive "so" in the recasting in the senior doctor statements and a shift to more technical, precise language. Table 3 provides an example of these language features.

Of note in the findings on generic structure in these consult calls is the difference in stages and interactivity in these examples compared to the ISBAR communication protocol for handovers, with the latter representing the handover as a monologic communication event (Eggins \& Slade, 2013).

\section{Table 3}

Senior Doctor Recasting the IMG Statements Using "So"(Pryor \& Woodward-Kron, 2014, p. 49)

\begin{tabular}{c|c|l}
\hline Turn & Speaker & Transcript R4 \\
\hline 16 & SD & $\begin{array}{l}\text { and tell me, um, is he a is he awake and talking at the moment? = } \\
=\text { yes, he's awake and talking (he's a) GCS of fifteen }\end{array}$ \\
\hline 17 & IMG & Okay, so his airway's patent = \\
\hline 18 & SD & his airway's patent = \\
\hline 19 & IMG & = and he's breathing = \\
\hline 20 & SD & yes. \\
\hline 22 & MG & and what are his oxygen sats at the moment? \\
\hline 23 & SD & um, at ninety four, with a mask on at fifteen maximum = \\
\hline 24 & SD & $=$ right, so he's hypoxic on oxygen. \\
\hline
\end{tabular}

= indicates follow on or interruption

\section{Conclusion}

Discourse analysis of texts, written and spoken, can make visible to health professional educators what the valued discursive practices of HPE and practice are and complement other methodologies used in HPE research. This article has attempted to raise awareness of the possible applications and contributions of discourse analysis to HPE and to introduce genre theory, one approach to understanding how texts are socially constructed to achieve their communicative goals. Researchers interested in doing discourse analysis can read further about discourse analysis in HPE journals (Hodges, 2008; Kärreman \& Levay, 2017); reading primary sources is also recommended. Discourse analysis is essentially an interdisciplinary approach to researching HPE and practice, so collaboration with humanities and social science researchers is also recommended.

\section{Funding and conflicts of interest statement}

No funding or conflict of interest to declare. 
DISCOURSE ANALYSIS FOR HEALTH PROFESSIONAL EDUCATION

\section{References}

Bernstein, B. (1990). The structuring of pedagogic discourse: Class, codes, and control (Vol. 3). Routledge. https://doi.org/10.4324/9780203011263

Boyd, V. A., Whitehead, C. R., Thille, P., Ginsburg, S., Brydges, R., \& Kuper, A. (2018). Competency-based medical education: The discourse of infallibility. Medical Education, 52(1), 45-57. https://doi.org/10.1111/medu.13467

Brown, J., Nestel, D., Clement, T., \& Goldszmidt, M. (2018). The supervisory encounter and the senior GP trainee: Managing for, through and with. Medical Education, 52(2), 192-205. https://doi.org/10.1111/medu.13468

Brown, P., \& Levinson, S. C. (1987). Politeness. Some universals in language usage. Cambridge University Press.

Christie, F. (1994). Developing an educational linguistics for English language teaching. Functions of Language, 1(1), 95-127. https://doi.org/10.1075/ fol.1.1.06 chr

Christie, F. (2002). Classroom discourse analysis: A functional perspective. Continuum. de la Croix, A., \& Skelton, J. (2013). The simulation game: An analysis of interactions between students and simulated patients. Medical Education, 47(1), 49-58. https://doi.org/10.1111/medu. 12064

Dornan, T. (2014). When I say ... discourse analysis. Medical Education, 48(5), 466-467. https://doi.org/10.1111/medu.12291

Eggins, S., \& Slade, D. (1997). Analysing casual conversation. Cassell.

Eggins, S., \& Slade, D. (2013). Clinical handover as an interactive event: Informational and interactional communication strategies in effective shift-change handovers. Communication \& Medicine, 9(3), 215-227. https://doi.org/10.1558/ cam.v9i3.215

Fairclough, N. (2001). Language and power. Pearson Education.

Goffman, E. (1981). Forms of talk. Unversity of Pennsylvania Press.

Halliday, M. A. K. (1978). Language as a social semiotic: The social interpretation of language and meaning. Edward Arnold.

Hodges, B. (2008). Discourse analysis. BMJ, 337, a879. https://doi.org/10.1136/bmj. a879

Howe, A., Barrett, A., \& Leinster, S. (2009). How medical students demonstrate their professionalism when reflecting on experience. Medical Education, 43(10), 942-951. https://doi.org/10.1111/j.1365-2923.2009.03456.x

Imafuku, R., \& Bridges, S. (2016). Guest editors' introduction: Special issue on analyzing interactions in PBL-Where to go from here? Interdisciplinary Journal of Problem-Based Learning, 10(2), Article 6. https://doi.org/10.7771/15415015.1648 
Imafuku, R., Kataoka, R., Mayahara, M., Suzuki, H., \& Saiki, T. (2014). Students' experiences in interdisciplinary problem-based learning: A discourse analysis of group interaction. The Interdisciplinary Journal of Problem Based Learning, 8(2), Article 1. https://doi.org/10.7771/1541-5015.1388

Kärreman, D., \& Levay, C. (2017). The interplay of text, meaning and practice: Methodological considerations on discourse analysis in medical education. Medical Education, 51(1), 72-80. https://doi.org/10.1111/medu.13212

Kurtz, S., \& Silverman, J. (1996). The Calgary-Cambridge referenced observation guides: An aid to defining the curriculum and organizing the teaching in communication training programmes. Medical Education, 30(2), 83-89. https:// doi.org/10.1111/j.1365-2923.1996.tb00724.x

Lave, J., \& Wenger, E. (1991). Situated learning: Legitimate peripheral participation. Cambridge University Press. https://doi.org/10.1017/CBO9780511815355

Lingard, L. (2007). The rhetorical "turn" in medical education: What have we learned and where are we going? Advances in Health Sciences Education, 12(2), 121-133. https://doi.org/10.1007/s10459-006-9046-y

Lingard, L., Schryer, C., Garwood, K., \& Spafford, M. (2003). "Talking the talk": School and workplace genre tensions in clerkship case presentations. Medical Education, 37(7), 612-620. https://doi.org/10.1046/j.1365-2923.2003.01553.x

Martin, J. R. (1993). Technicality and abstraction: Language for the creation of specialized texts. In M. A. K. Halliday \& J. R. Martin (Eds.), Writing science: Literacy and discursive power (pp. 166-202). Falmer Press.

Martin, J. R. (1997). Analysing genre: Functional parameters. In F. Christie \& J. R. Martin (Eds.), Genre and institutions: Social processes in the workplace and school (pp. 3-39). Continuum.

Martin, J. R. (2001). Language, register and genre. In A. Burns \& C. Coffin (Eds.), Analysing English in a global context. Routledge.

Mehan, H. (1979). Learning lessons: Social organization in the classroom. Harvard University Press.

Pryor, E., \& Woodward-Kron, R. (2014). International medical graduate doctor to doctor telephone communication: A genre perspective. English for Specific Purposes, 35, 41-53. https://doi.org/10.1016/j.esp.2013.12.001

Rees, C., \& Monrouxe, L. (2008). "Is it alright if I-um-we unbutton your pyjama top now?" Pronominal use in bedside teaching encounters. Communication and Medicine, 5(2), 171-181. https://doi.org/10.1558/cam.v5i2.171

Roberts, C., Wass, V., Jones, R., Sarangi, S., \& Gillett, A. (2003). A discourse analysis study of "good" and "poor" communication in an OSCE: A proposed new framework for teaching students. Medical Education, 37(3), 192-201. https://doi. org/10.1046/j.1365-2923.2003.01443.x

Rose, D. (2014). Analysing pedagogic discourse: An approach from genre and register. Functional Linguistics, 1(1), Article 11. https://link.springer.com/ article/10.1186/s40554-014-0011-4 
Sinclair, J., \& Coulthard, M. (1975). Towards an analysis of discourse. Oxford University Press.

Tai, S., Barr, C., \& Woodward-Kron, R. (2019). Towards patient-centred communication: An observational study of supervised audiology student-patient hearing assessments. International Journal of Audiology, 58(2), 97-106. https://doi. org/10.1080/14992027.2018.1538574

Whitehead, C., Kuper, A., Freeman, R., Grundland, B., \& Webster, F. (2014). Compassionate care? A critical discourse analysis of accreditation standards. Medical Education, 48(6), 632-643. https://doi.org/10.1111/medu.12429

Woodward-Kron, R. (2004). "Discourse communities" and "writing apprenticeship": An investigation of these concepts in undergraduate education students' writing. Journal of English for Academic Purposes, 3(2), 139-161. https://doi.org/10.1016/j. jeap.2003.09.001

Woodward-Kron, R. (2007). Negotiating meanings and scaffolding learning: Writing support for non-English speaking background postgraduate students. Higher Education Research and Development, 26(3), 139-161. https://doi. org/10.1080/07294360701494286

Woodward-Kron, R. (2008). More than just jargon:The nature and role of specialist language in learning disciplinary knowledge. Journal of English for Academic Purposes, 7(4), 234-249. https://doi.org/10.1016/j.jeap.2008.10.004

Woodward-Kron, R., \& Remedios, L. (2007). Classroom discourse in problem-based learning classrooms in the health sciences. Australian Review of Applied Linguistics, 30(1), 9.1-9.18. https://doi.org/10.2104/aral0709 